\title{
Lipid-based floating multiparticulate delivery system for bioavailability enhancement of berberine hydrochloride
}

\author{
Rakesh Mishra $^{1 *}$, Shashikant Dhole ${ }^{2}$ \\ ${ }^{1}$ Department of Pharmaceutics, Dr. D. Y. Patil Institute of Pharmaceutical Sciences and Research, Pune, India. \\ ${ }^{2}$ Department of Pharmaceutics, Modern College of Pharmacy, Pune, India.
}

\begin{tabular}{l}
\hline ARTICLE INFO \\
\hline Received on: $27 / 05 / 2019$ \\
Accepted on: $18 / 09 / 2019$ \\
Available online: $04 / 11 / 2019$
\end{tabular}

\section{Key words:}

Berberine hydrochloride, gelucire, solid dispersion, lipid floating multiparticulate, gastroretentive.

\begin{abstract}
The objective of the present investigation was to design and optimize lipid-based floating multiparticulate of Berberine hydrochloride (BERH), so as to increase its solubility and to reduce P-Glycoprotein mediated efflux in the intestine, hence to improve oral bioavailability. Solid dispersions were prepared using hydrophilic carriers gelucire 44/14 and gelucire 50/13 in different ratio. The prepared solid dispersion of BERH was further formulated into sustain release gastroretentive floating pellets using hydrophobic lipid carrier gelucire 43/01 as release retardant, sodium bicarbonate $\left(\mathrm{NaHCO}_{3}\right)$ and hydroxylpropyl methyl cellulose $\mathrm{K} 4 \mathrm{M}(\mathrm{HPMC} \mathrm{K} 4 \mathrm{M})$ as gas former and matrix polymer,

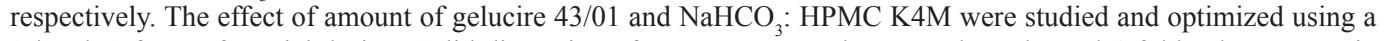
3-level, 2-factor, factorial design. Solid dispersion of BERH compared to pure drug showed 4-fold enhancement in aqueous solubility. The optimum system could float for more than 8 hours and showed $88.46 \%$ drug release in 8 hours. The pharmacokinetic study conducted in male Wistar rats indicated 2.32-fold increase in relative bioavailability of optimized formulation compare to the marketed tablet. The lipid-based floating pellets of BERH were obtained and could be an applicable choice to deliver BERH with improved bioavailability in effective use for various clinical applications.
\end{abstract}

\section{INTRODUCTION}

Berberine hydrochloride (BERH), a quaternary isoquinoline alkaloid, presents in various plants of Berberis species which are commonly found in the Eastern hemisphere (Kosalec et al., 2009). It has been historically used as an antidiarrheal agent in Ayurvedic and Chinese medicine (Chang, 1959). In the past few years, numerous studies have demonstrated the potential therapeutic applications of BERH including antidiabetic, anti-hyperlipidemic, anti-obesity, anti-arrhythmic, and anti-cancer (Gao et al., 2013; Jantova et al., 2003; Kettmann et al., 2004; Kong et al., 2004; Lee et al., 2006; Sanchez, 1996; Shen et al., 2014; Tsai and Tsai, 2004). However, the systemic bioavailability of BERH is very low due to its poor water solubility

\section{"Corresponding Author}

Rakesh Mishra, Department of Pharmaceutics, Dr. D. Y. Patil Institute of Pharmaceutical Sciences and Research, Pune, India.

E-mail: mishrarakesh287@gmail.com and dissolution rate which limits its clinical use (Tan et al., 2011). $\mathrm{BERH}$ is also a P-glycoprotein substrate (P-gp) results into active efflux from the intestine (Maeng et al., 2002; Pan et al., 2002; Zhang et al., 2013). In addition, BERH has a shorter biological halflife of 2-2.5 h (Alolga et al., 2016). Hence, it is necessary to improve the solubility and bioavailability of BERH so that it can be effectively used in many clinical applications.

In recent years, some studies have explored the use of P-gp inhibitors, permeation enhancers and lipid-based delivery systems to enhance the oral bioavailability of BERH (Fan et al., 2013; Ke et al., 2015; Khayam et al., 2018; Sailor et al., 2015; Wei et al., 2011; Zhu et al., 2013). However, P-gp inhibitors possess their own pharmacological effects and might leads to toxic effects while use of permeation enhancers suffers with the drawback of compromised integrity of intestinal mucosa (Davis, 2005). Among the lipid-based systems, self-microemulsifying systems, solid lipid nanoparticle and liposomes of BERH were developed showed significant enhancement in bioavailability but faces the problems of either low drug loading capacity or poor long term stability (Sailor et al., 2015). Solid dispersion technique is one of the areas that have been 
extensively used to improve the solubility, dissolution rate and oral absorption of poorly water-soluble drugs (Douroumis et al., 2007; ElBadry and Fathy 2006; 2015; Thybo et al., 2007). On the other hand, gastroretentive dosage forms might be useful for P-gp substrate drugs because they allow continuous delivery of drug to the proximal part of the gastrointestinal tract (GIT) (Hoffman et al., 2004; Kagan and Hoffman, 2008; Streubel et al., 2006). Among all the gastroretentive systems, due to minimum affect on GIT motility, floating drug delivery systems (FDDS) are considered suitable and preferable (Kotreka and Adeyeye, 2011; Reddy and Murthy, 2002; Strusi et al., 2008). A wide range of single unit and multiparticulate FDDS were developed, due to reduce inter and intra subject variabilities in drug absorption and lower chances of dose dumping the multiparticulate FDDS were chosen over single unit system (Bulgarelli et al., 2000; Iannuccelli et al., 1998; Streubel et al., 2003).

Gelucires are a family of vehicles derived from mixtures of mono, di, and triglycerides with polyethylene glycol (PEG) esters of fatty acids. Gelucires are available with a range of properties depending on their Hydrophilic Lipophilic Balance (1-18) and melting point $\left(33^{\circ} \mathrm{C}-65^{\circ} \mathrm{C}\right)$ range (Anaoui and Vergnaud, 1998; Sheu and Hsia 2001). The gelucires containing only PEG ester such as gelucire 44/14 and gelucire 50/13 are hydrophilic in nature and profoundly used for solubility enhancement (Pawar et al., 2012; Pestieau et al., 2015; Seo et al., 2003; Sruti et al., 2013; Yang et al., 2007). That composed of only glycerides or mixtures of glycerides and PEG esters such as gelucire 43/01 due to extreme hydrophobicity used in the preparation of sustained release and gastroretentive formulations (Barker et al., 2003; Jain and Jangdey, 2009).

The present research work aims to enhance the oral bioavailability of BERH. In the present study solid dispersion of BERH was prepared by fusion method using gelucire 44/14 and gelucire 50/13 to enhance its solubility and dissolution rate. Further the prepared solid dispersion of BERH was formulated into sustain release gastroretentive floating pellets so as to reduce its P-gp mediated efflux in the intestine. The sustain release floating pellets was prepared using hydrophobic lipid carrier gelucire 43/01 as release retardant, sodium bicarbonate $\left(\mathrm{NaHCO}_{3}\right)$ and hydroxylpropyl methyl cellulose K4M (HPMC K4M) as gas former and matrix polymer, respectively. The combined effect of amount of gelucire 43/01 and $\mathrm{NaHCO}_{3}$ is to HPMC K4M on the floating behavior and drug release from floating pellets were studied and optimized using, a 3-level, 2-factor, factorial design.

\section{MATERIALS AND METHODS}

\section{Materials}

Berberine Hydrochloride was purchased from Yucca Enterprises, Mumbai, India. Gelucire 43/01, Gelucire 44/14, Gelucire 50/13 and Compritol 888 were provided as gift sample by Gattefosse India Pvt. Ltd., Mumbai, India. $\mathrm{NaHCO}_{3}$, HPMC K4M and Microcrystalline cellulose obtained from Himedia Laboratories, Mumbai, India. All the other reagents used in the study were of analytical grade.

\section{Preparation of solid dispersion by fusion method}

Solid dispersion of BERH with gelucire 44/14 and gelucire 50/13 in different weight ratios of 1:1, 1:1.5, 1:2, 1:3 and 1:4 were prepared by fusion method (Shaker, 2018) (Table 1). Accurately weighed amount of gelucire was heated $10^{\circ} \mathrm{C}$ above the melting point
Table 1. Solubility studies of Berberine Hydrochloride solid dispersion.

\begin{tabular}{lcccc}
\hline Batch code & $\begin{array}{c}\text { Berberine } \\
\text { hydrochloride } \\
(\mathbf{m g})\end{array}$ & $\begin{array}{c}\text { Gelucire } \\
\mathbf{4 4 / 1 4}(\mathbf{m g})\end{array}$ & $\begin{array}{c}\text { Gelucire } \\
\mathbf{5 0 / 1 3}(\mathbf{m g})\end{array}$ & $\begin{array}{c}\text { Solubility } \\
(\mathbf{m g} / \mathbf{m l})\end{array}$ \\
\hline Pure BERH & 100 & - & - & $0.718 \pm 0.02$ \\
B 1 & 100 & 100 & - & $1.203 \pm 0.19$ \\
B 2 & 100 & 150 & - & $1.791 \pm 0.23$ \\
B 3 & 100 & 200 & - & $2.661 \pm 0.16$ \\
B 4 & 100 & 300 & - & $2.673 \pm 0.08$ \\
B 5 & 100 & 400 & - & $2.689 \pm 0.15$ \\
B 6 & 100 & - & 100 & $1.243 \pm 0.07$ \\
B 7 & 100 & - & 150 & $1.816 \pm 0.11$ \\
B 8 & 100 & - & 200 & $2.841 \pm 0.15$ \\
B 9 & 100 & - & 300 & $2.848 \pm 0.04$ \\
B 10 & 100 & - & 400 & $2.859 \pm 0.13$ \\
\hline
\end{tabular}

Mean \pm S.D.; $n=3$.

in porcelain dish followed by addition of BERH with continuous stirring. The prepared mass was cooled at room temperature for 24 hours. The obtained dried solid dispersions were grinded in a mortar and pestle and sieved through 60 mesh. The samples were subsequently stored in desiccators until the next experiments.

\section{Solubility screening studies}

To determine the improvement in solubility of BERH solid dispersion prepared with gelucire (44/14 and 50/13), saturated solubility studies were performed. An excess amount of BERH solid dispersion was added into conical flask containing $10 \mathrm{ml}$ of distilled water. The conical flask was shaken for 48 hours on water bath shaker at room temperature (Neolab, Mumbai) (Daravath et al., 2015; Khayam et al., 2018). Subsequently the content of flask was filtered through Whatman filter paper and the filtrate was analyzed spectrophotometrically at $263 \mathrm{~nm}$ (Shimadzu, 1700, Japan).

\section{Preparation of sustain release floating pellets}

From the results of solubility screening studies (Table 1), the BERH solid dispersion batch-B 8 (BERH: Gelucire 50/13; in ratio $1: 2$ ) was selected for preparation of sustain release floating pellets. The BERH floating pellets were prepared by extrusion and spheronization technique. Compritol 888 and gelucire 43/01 screened as release-retarding polymer. Microcrystalline cellulose, $\mathrm{NaHCO}_{3}$ and HPMC K4M used as spheronizing aid, gas former and matrix agent, respectively. Compritol 888 and gelucire 43/01 were melted in porcelain dish at their melting points. The BERH solid dispersion equivalent to $100 \mathrm{mg}$ of $\mathrm{BERH}$ (batch-B8), $\mathrm{NaHCO}_{3}$, HPMC K4M and microcrystalline cellulose were added into the molten mass of release-retarding polymer, mixed well and passed through sieve no.16 to get the extrudates. Extrudates were then transferred to spheronizer (Shakti Pharmatech, Ahmedabad, India) and spheronized at $700 \mathrm{rpm}$ for about $05 \mathrm{~min}$ to obtain the pellets. The obtained floating pellets were dried for 24 hours at room temperature.

\section{Experimental design}

A 3-level, 2-factor, 09 run experiment factorial design was adopted for optimization procedure. Amount of gelucire 43/01 (X1) and $\mathrm{NaHCO}_{3}:$ HPMC K4M in the ratio of 1:0.5 (X2) selected as independent variables (Table 2). The dependent variables were 
Table 2. Independent variables levels in experimental design.

\begin{tabular}{lcccccc}
\hline & \multicolumn{3}{c}{ Coded value } & \multicolumn{3}{c}{ Actual value } \\
\cline { 2 - 7 } Factors & Low & Medium & High & Low & Medium & High \\
\hline $\begin{array}{l}\text { Gelucire 43/01-X1 } \\
(\% \text { w/w of BERH solid dispersion })\end{array}$ & -1 & 0 & +1 & 20 & 25 & 30 \\
$\begin{array}{l}\text { NaHCO }: \text { HPMC K4M - X2 } \\
(\% \text { w/w of BERH solid dispersion) }\end{array}$ & -1 & 0 & +1 & 10 & 15 & 20 \\
\hline
\end{tabular}

Table 3. Formulation compositions.

\begin{tabular}{lcc}
\hline Batch no. & Gelucire $\mathbf{4 3 / 0 1}(\% \mathbf{w} / \mathbf{w})$ & $\mathbf{N a H C O}_{3}:$ HPMC K4M (\% w/w $)$ \\
\hline B 11 & 20 & 10 \\
B 12 & 25 & 10 \\
B 13 & 30 & 10 \\
B 14 & 20 & 15 \\
B 15 & 25 & 15 \\
B 16 & 30 & 15 \\
B 17 & 20 & 20 \\
B 18 & 25 & 20 \\
B 19 & 30 & 20 \\
B 20* & 27.5 & 20 \\
\hline
\end{tabular}

*Formulation prepared using numerical optimization function based upon desirability approach in Design-expert ${ }^{\mathbb{B}}$ software.

percent drug release in 1 hour (Y1), 8 hours (Y2) and total floating time (Y3). The formulation compositions were shown in (Table 3). Design-expert ${ }^{\circledR}$ software (Version10, Stat-Ease) used to carry out Response surface modelling, analysis of variance (ANOVA) and model graphs studies.

\section{Evaluation of floating pellets}

\section{Calibration curve of Berberine Hydrochloride in $0.1 \mathrm{~N} \mathrm{HCl}$}

$10 \mathrm{mg}$ of BERH accurately weighed and was dissolved in $100 \mathrm{ml} 0.1 \mathrm{~N} \mathrm{HCl}$ to get stock solution of $100 \mu \mathrm{g} / \mathrm{ml}$. The stock solution was further diluted with $0.1 \mathrm{~N} \mathrm{HCl}$ to obtain solutions in concentration range of 1 to $20 \mu \mathrm{g} / \mathrm{ml}$. Absorbance of these solutions were determined spectrophotometrically (Shimadzu 1700, Japan) at $263 \mathrm{~nm}$.

\section{Fourier Transfsorm Infra-Red (FTIR) spectrum}

The FTIR scans of BERH, gelucire 50/13, gelucire $43 / 01$ and physical mixture of BERH with gelucire (50/13 and 43/01) were obtained using FTIR (Shimadzu, 8400S, Japan) (Khayam et al., 2018). The dry samples were separately mixed and triturated thoroughly with potassium bromide. The infrared spectrums were recorded and the spectral analysis was done between 400 to $4,000 \mathrm{~cm}^{-1}$.

\section{Physical characterization and drug content}

To evaluate the micromeritic properties of floating pellets Carr's index, Hausner's ratio and angle of repose were determined. The hardness of the pellets was determined using digital hardness tester (Veego, India). Friability of the pellet formulations was determined using friabilator (Veggo Friability Tester, India). $10 \mathrm{~g}$ of pellets were kept into friabilator and the percentage weight loss after 200 revolutions was determined (Kim et al., 2007; Parmar et al., 2016). The drug content in each formulation was determined by taking floating pellets equivalent to about $100 \mathrm{mg}$ of $\mathrm{BERH}$, grounded and transferred into a volumetric flask containing 0.1 $\mathrm{N} \mathrm{HCl}$. The mixture was sonicated for 30 minutes to ensure complete extraction of drug in $0.1 \mathrm{~N} \mathrm{HCl}$. The solution was further filtered, diluted with appropriate amount of $0.1 \mathrm{~N} \mathrm{HCl}$ and assayed spectrophotometrically at $263 \mathrm{~nm}$ (Shimadzu, 1700, Japan) $(n=3)$.

\section{Floating studies}

Hundred unit pellets were placed in $900 \mathrm{ml}$ of $0.1 \mathrm{~N} \mathrm{HCl}$ maintained at $37^{\circ} \mathrm{C} \pm 0.5^{\circ} \mathrm{C}$ in USP Type -II dissolution apparatus (Veego DA-8D, India). The medium was agitated by paddle at 50 rpm. The time taken by the pellets to rise over the surface of medium (floating lag time) and total floating time was measured visually (Kim et al., 2007; Parmar et al., 2016; Rajinikanth et al. 2008).

\section{In vitro drug release study}

The release of BERH from the floating pellet formulations were determined in triplicates using USP Type -II dissolution apparatus (Veego DA-8D, India). Pellets equivalent to $100 \mathrm{mg}$ of drug were accurately weighed and transferred into 900 $\mathrm{ml}$ of $0.1 \mathrm{~N} \mathrm{HCl} \mathrm{kept} \mathrm{at} 37^{\circ} \mathrm{C} \pm 0.5^{\circ} \mathrm{C}$ on $50 \mathrm{rpm}$ (Elsamaligy et al., 2015; Pagariya et al., 2013). At predetermined time intervals (i.e., 1, 2, 3, 4, 5, 6, and 8 hours), $5 \mathrm{ml}$ of aliquots was withdrawn and immediately replaced by the same volume of fresh dissolution medium to maintain the sink condition. To calculate the drug release, aliquots were filtered and analyzed by UV spectrophotometer at $263 \mathrm{~nm}$.

To understand the mechanism of drug release kinetics, the obtained drug release data of optimized floating pellets formulation was analyzed according to the mathematical models like zero order model, first order model, Korsmeyer-Peppas model and Higuchi model (Costa and Lobo, 2001; Higuchi, 1963; Korsmeyer et al., 1983; Lopes et al., 2006; Ritger and Peppas, 1987).

\section{Statistical optimization}

The obtained data of dependent variables i.e. total floating time, percent drug release in 1 hour and 8 hours for all formulations were analyzed by Design-expert ${ }^{\circledR}$ software. Polynomial models for all the responses were generated. The suggested model based upon the values of standard deviation, multiple correlation coefficient $\left(R^{2}\right)$ and adjusted multiple correlation coefficient (adjusted $R^{2}$ ) was selected and further analyzed by ANOVA to determine significant model terms (Venkata et al., 2012). The $\mathrm{P}$ value, regression equation of the responses and response surface plots were also 
studied. To determine the optimum level of independent variables for the formulation numerical optimization function based upon desirability approach was used.

\section{Stability studies}

As per ICH guidelines the optimized BERH floating pellet formulation was subjected to accelerated stability studies. The sample was stored in $10 \mathrm{ml}$ open glass vials at $40^{\circ} \mathrm{C} / 75 \%$ relative humidity for three months. Pellet sample were observed for drug content, total floating time and drug release at $8 \mathrm{~h}$ after first, second and third month (Maurya et al., 2012).

In vivo pharmacokinetics-study design

Institutional Animal Ethical Committee (DYPIPSR/ IAEC/18-19/P-10) approval was obtained to conduct In-vivo pharmacokinetics studies in male Wistar rats. The study was designed to compare the formulated BERH floating pellets with marketed preparation. Twelve Wistar rats weighing 180-200 g were separated randomly into two groups, and fasted overnight with free access to water. BERH floating pellets and marketed preparation $(25 \mathrm{mg} / \mathrm{kg})$ was administered orally into respective groups (Zhu et al., 2013). At predetermined time intervals (0.25, $0.5,1,2,4,8,12$, and 24 hours) post oral dose, $0.5 \mathrm{ml}$ of blood samples were collected. Plasma was immediately separated by centrifuging at $4,000 \mathrm{rpm}$ for 15 minutes and stored at $-20^{\circ} \mathrm{C}$ until analysis.

\section{HPLC analysis of berberine hydrochloride in plasma}

HPLC method was employed to determine plasma concentrations of BERH. The mobile phase consisted of acetonitrile and phosphate buffer $\mathrm{pH} 3.0$ (40:60). The flow rate kept was $1 \mathrm{ml} /$ minute and the UV detector was set at wavelength of 263 $\mathrm{nm}$ (Guo et al., 2017). Stock solution of BERH (100 $\mu \mathrm{g} / \mathrm{ml})$ was prepared using mobile phase and further diluted with mobile phase to obtain working standard solutions in concentration range of 5 to $70 \mu \mathrm{g} / \mathrm{ml}$. The calibration curve of working standard solutions was obtained and used for estimation of BERH in plasma. A linear relationship was observed between the BERH concentration and the peak areas of BERH with a high correlation coefficient $\left(r^{2}=\right.$ 0.995). For the estimation of BERH content in rat plasma, a 0.1 $\mathrm{ml}$ of plasma sample was added into $0.9 \mathrm{ml}$ of acetonitrile and centrifuged for 15 minutes at $10,000 \mathrm{rpm}$. The supernatant liquid obtained was filtered through $0.2 \mu$ filter and $20 \mu$ was injected into the HPLC column. Palmatine was used as an internal standard at a concentration of $1 \mu \mathrm{g} / \mathrm{ml}$. The analysis was carried out on Shimadzu HPLC LC20 AD (Shimadzu Corporation, Japan) using reversed-phase HPLC column (Kromasil, $4.6 \times 250 \mathrm{~mm}, 5 \mu \mathrm{m}$, Shreetech Associates; Mumbai, India).

\section{Pharmacokinetic analysis}

The pharmacokinetic parameters such as peak plasma concentration $\left(C_{\max }\right)$, time to reach peak plasma levels $\left(T_{\max }\right)$, area under the curve (AUC), mean residence time (MRT), elimination rate constant $\left(K_{\mathrm{e}}\right)$ and relative bioavailability were estimated using PK solver software (version 2.0). The evaluated pharmacokinetic parameters were statistically analyzed using ANOVA and the difference less than the probability level 0.05 was considered statistically significant.

\section{RESULTS AND DISCUSSION}

\section{Result of preliminary screening}

The determined aqueous solubility of BERH at room temperature was found to be $0.71 \mathrm{mg} / \mathrm{ml}$. To improve the solubility of drug, hydrophilic carrier gelucire 50/13 and gelucire 44/14 was screened. Solid dispersion in different weight ratios $(1: 1,1: 1.5,1: 2,1: 3$, and 1:4) was prepared by fusion method. The solubility studies of prepared solid dispersions were conducted in distilled water at $25^{\circ} \mathrm{C}$. The results of solubility studies for prepared solid dispersion using different hydrophilic carriers indicated greater solubility of drug with gelucire 50/13 compared to gelucire 44/14 (Table 1). As the amount of carrier increases, the solubility increased proportionally but after 1:2 ratio (drug:carrier) no significant increase in solubility was observed by increasing the carrier concentration. The solubility of BERH solid dispersion increased up to 4-folds compared to pure BERH.

Further from the results of solubility screening studies, the BERH solid dispersion (BERH: Gelucire 50/13; in ratio 1:2) was chosen for preparation of sustain release floating pellets. Compritol 888 and gelucire 43/01 (20, 25 and 30\% w/w of solid dispersion) were screened as release-retarding polymer. The obtained results for in vitro drug release indicated that compritol 888 was unable to retard the drug release after 4 hours (data not shown). The floating pellets prepared with gelucire 43/01 in various amount were found to float for up to 3 to 4 hours with initial burst release and retarded the drug release as a function of the amount of gelucire 43/01. In preliminary screening studies of release-retarding polymer, considering the results of in vitro drug release studies gelucire 43/01 was preferred over compritol 888 as release retardant for the further studies. To strengthen the floating ability additionally, $\mathrm{NaHCO}_{3}$ and $\mathrm{HPMC} \mathrm{K} 4 \mathrm{M}$ in the ratio of 1:0.5 $(10,15$, and $20 \% \mathrm{w} / \mathrm{w}$ of solid dispersion) is incorporated as gas former agent and swellable polymer, respectively, in the preparation of BERH floating pellets.

Subsequently, to evaluate the combined effect of percentage of gelucire $43 / 01$ and $\mathrm{NaHCO}_{3}$ is to HPMC K4M on the floating behavior and drug release from floating pellets, a 3-level, 2 -factor, factorial design was used. The dependent variables taken as response were total floating time, percent drug release in 1 and 8 hours.

\section{Evaluation of gastroretentive floating pellets}

Spectroscopic studies

The $\lambda_{\text {max }}$ of BERH in $0.1 \mathrm{~N} \mathrm{HCl}$ was found to be $263 \mathrm{~nm}$. The calibration curve of BERH obtained in $0.1 \mathrm{~N} \mathrm{HCl}$ was found to be linear in the studied range and equation of the regression analysis was also generated as indicated in (Fig. 1).

\section{Fourier Transform Infra-Red (FTIR) spectrum}

The IR spectrum of BERH, gelucire 50/13, gelucire $43 / 01$ and physical mixture of BERH with gelucire (50/13 and 43/01) was obtained by using FTIR (Fig. 2). The FTIR spectra of BERH showed characteristic peaks at $700-1,300 \mathrm{~cm}^{-1}$ (skeletal C-C vibrations), $1,033.88 \mathrm{~cm}^{-1}$ (C-O), 1,251.84 $\mathrm{cm}^{-1}$ (C-O-C stretching), $1,332.86$ to $1,033.88 \mathrm{~cm}^{-1}$ (in plane $=\mathrm{C}-\mathrm{H}$ bending) 


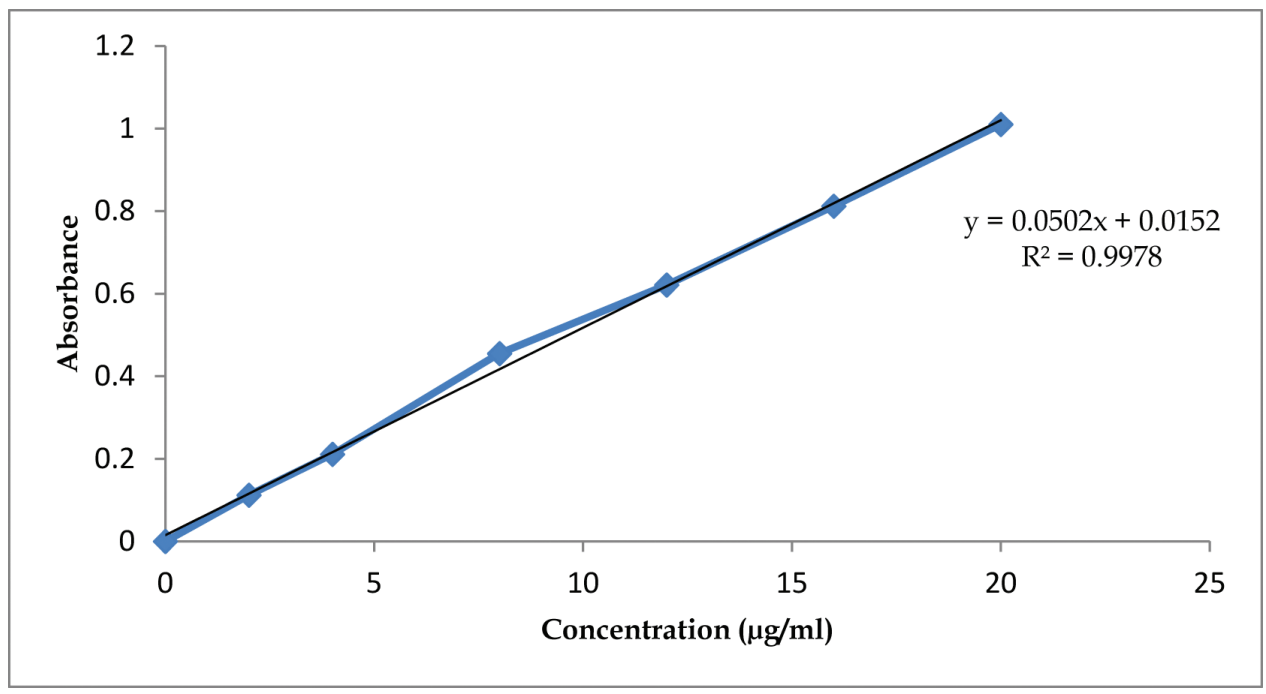

Figure 1. Calibration curve of Berberine Hydrochloride in $0.1 \mathrm{~N} \mathrm{HCl}$ at $263 \mathrm{~nm}$.

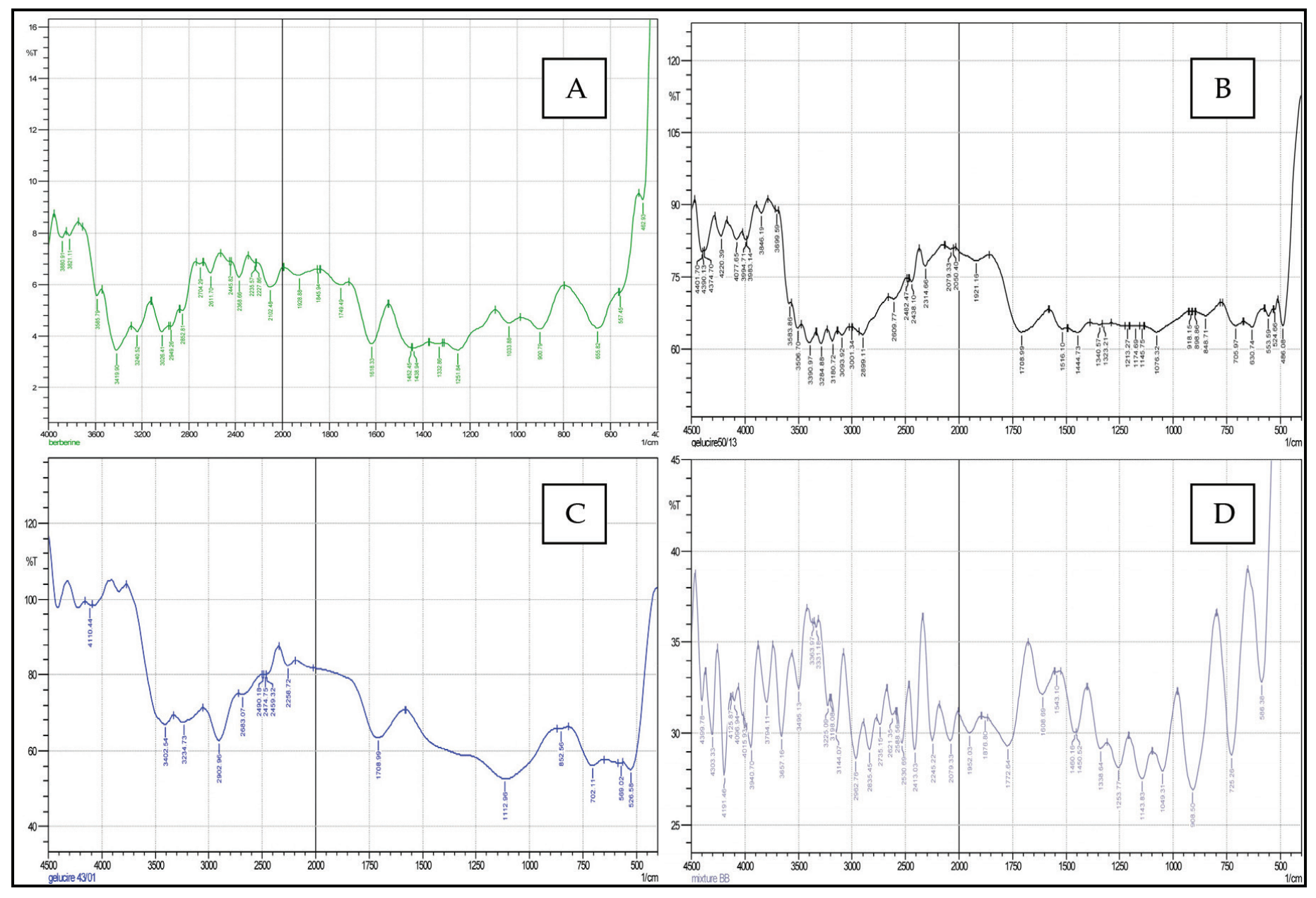

Figure 2. FTIR scans of A. Berberine Hydrochloride, B. Gelucire 50/13, C. Gelucire 43/01, D. Physical mixture (BERH \& Gelucire).

1,452.45 and 1,618.33 $\mathrm{cm}^{-1}$ (aromatic $\mathrm{C}=\mathrm{C}$ stretching), 2,852.81 $\mathrm{cm}^{-1}$ (C-H stretch). The characteristic peaks for gelucire (50/13 and $43 / 01$ ) are 3,699.59-3,180.72 $\mathrm{cm}^{-1}$ (OH stretching), 3,001.34 and $2,899.11 \mathrm{~cm}^{-1}$ (C-H stretching), $1,708.99 \mathrm{~cm}^{-1}$ (C=C stretching),
1,444.73 to $1,076.32 \mathrm{~cm}^{-1}$ (C-H bending), 1,323.21, 1,213.27 $\mathrm{cm}^{-1}$ (C-O-C stretching), 1,145.75, $1,174.69 \mathrm{~cm}^{-1}$ (C-O stretching), $848.71 \mathrm{~cm}^{-1}$ (C-C stretching) and $705.97 \mathrm{~cm}^{-1}$ ( $\mathrm{C}=\mathrm{C}$ bending). The FTIR spectra of physical mixture showed the characteristic 
peaks of drug and gelucire (50/13 and 43/01) with negligible shift in wave numbers indicated compatibility of BERH with gelucire.

\section{Physical characterization and drug content}

The results of micromeritic analysis indicated good flow behavior of pellet formulations. Carr's index and Hausner's ratio ranged from $14.89 \pm 1.1 \%$ to $18.43 \pm 0.8 \%$ and $1.19 \pm 0.2$ to $1.22 \pm 0.4$, respectively. The values obtained for angle of repose were in the range of $23.38 \pm 1.6^{\circ}$ to $25.12 \pm 1.9^{\circ}$. Hardness of the prepared pellets was in the range of $0.47 \pm 0.04$ to $0.92 \pm 0.01 \mathrm{~kg} /$ $\mathrm{cm}^{2}$. The obtained friability values of the pellets formulation ranged from $0.33 \pm 0.2 \%$ to $0.49 \pm 0.1 \%$. This may be attributed to the waxy nature of gelucires. The drug content in all the floating pellet formulation was determined by UV spectroscopy method. It was found to be between $96.45 \pm 1.5 \%$ to $97.85 \pm 1.2 \%$ which indicated good content uniformity of BERH in prepared floating pellets.

\section{Floating studies}

The gastro-floating studies of prepared BERH pellets were conducted in $0.1 \mathrm{~N} \mathrm{HCl}$. Floating lag time and total floating time of pellets was measured visually. In the preliminary screening studies, it was observed that pellets prepared alone with gelucire $43 / 01$ in various ratios $(20,25$, and $30 \% \mathrm{w} / \mathrm{w})$ were floated for up to 3 to 4 hours with zero floating lag time. As gelucire 43/01 is a hydrophobic lipid which imparts hydrophobicity to the pellet surface and could be a probable reason behind zero floating lag time behavior (Shimpi et al., 2004). Moreover to increase the total floating time additionally $\mathrm{NaHCO}_{3}$ which generates carbon dioxide $\left(\mathrm{CO}_{2}\right)$ in the presence of acidic media and swellable polymer HPMC K4M to entrap the generated $\mathrm{CO}_{2}$ inside the dosage form was incorporated in the preparation of BERH floating pellets. In the present study, the ratio of $\mathrm{NaHCO}_{3}$ : $\mathrm{HPMC} \mathrm{K} 4 \mathrm{M}$ was kept constant (1:0.5) and amount was varied (10, 15, and 20\% $\mathrm{w} / \mathrm{w})$. However, the addition of gas former agent $\left(\mathrm{NaHCO}_{3}\right)$ and swellable polymer (HPMC K4M) doesn't affected the floating lag time, all prepared pellet formulation batches rise over the surface of medium with zero floating lag time. The total floating time of the BERH pellets was increased significantly and $80 \%-90 \%$ of pellets remained floating for a period of 5.2 to 8.6 hours shown in (Table 4). The $10 \% \mathrm{w} / \mathrm{w}$ and $15 \% \mathrm{w} / \mathrm{w}$ amount of $\mathrm{NaHCO}_{3}: \mathrm{HPMC}$ $\mathrm{K} 4 \mathrm{M}$ was unable to ensure the buoyancy for longer period of time.
This could be attributed due to reduced amount of $\mathrm{NaHCO}_{3}: \mathrm{HPMC}$ $\mathrm{K} 4 \mathrm{M}$, the medium penetration was rapid but unable to generate sufficient $\mathrm{CO}_{2}$ to provide buoyancy for longer duration. On the other side as the amount of $\mathrm{NaHCO}_{3}: \mathrm{HPMC} \mathrm{K} 4 \mathrm{M}$ increases above $15 \% \mathrm{w} / \mathrm{w}$ the total floating time of pellets observed were $\geq 8$ hours. This could be explained as higher level of $\mathrm{NaHCO}_{3}: \mathrm{HPMC}$ $\mathrm{K} 4 \mathrm{M}$ used in the current study was able to generate sufficient $\mathrm{CO}_{2}$, swelling and hydration characteristics of HPMC K4M facilitated entrapment of generated $\mathrm{CO}_{2}$ inside the hydrating gel network, thus strengthen the floating ability of the pellets. Hence hydrophobicity provided by gelucire $43 / 01$ and gas generating mechanism ( $\mathrm{NaHCO}_{3}: \mathrm{HPMC} \mathrm{K} 4 \mathrm{M}$ ) collectively improved the floating behavior of prepared BERH pellets.

\section{In vitro drug release study}

The in vitro release profile of unprocessed BERH and prepared BERH solid dispersion formulation (batch-B 8) were studied in $0.1 \mathrm{~N} \mathrm{HCl}$ indicated in Figure 3. The unprocessed BERH and BERH solid dispersion showed about $24.39 \%$ and $98.59 \%$ drug release in 2 hours, respectively. The pure drug exhibited a low dissolution rate due to its poor intrinsic solubility. However, dissolution of the drug is enhanced significantly from the prepared solid dispersion (batch-B 8). The improvement in dissolution rate could be attributed to the solubilization action of the used hydrophilic carrier gelucire 50/13 (Kawakami et al., 2004; Mehuys et al., 2004; Svensson et al., 2004). The BERH solid dispersion (batch - B 8) was chosen further for preparation of sustain release floating pellets (batch-B11 to B 19). Gelucire 43/01 (20, 25, and 30\% w/w of solid dispersion) was used as release-retarding polymer. The invitro dissolution studies of prepared sustain release floating pellets were also performed shown in Figure 4 . As the amount of gelucire 43/01 increased significant retardation in drug release was observed. The sustain release floating pellets prepared with $20 \% \mathrm{w} / \mathrm{w}$ and $25 \%$ w/w of gelucire 43/01 showed initial burst release $\left(Q_{1}\right.$ ranging from $40.01 \%$ to $37.68 \%$ and $30.89 \%$ to $25.17 \%$, respectively) followed by sustained release with above $90 \%$ drug release in $8 \mathrm{~h}$ (Table 4 ). However, the pellets prepared with $30 \% \mathrm{w} / \mathrm{w}$ of gelucire showed initial 1 hour release in the range of $18.73 \%$ to $14.80 \%$ and $76.78 \%$ to $70.35 \%$ in 8 hours. The result of dissolution studies suggested that as the amount of gelucire 43/01 increases it minimizes burst release and sustained the drug release. This could be attributed due to the

Table 4. Response data of batches B 11-B 20.

\begin{tabular}{cccc}
\hline \multirow{2}{*}{ Batch no. } & Average drug release in $\mathbf{1}$ hour (\%) & Average drug release in 8 hours (\%) & \multicolumn{2}{c}{ Total floating time (h) } \\
\hline 11 & $\boldsymbol{Y}_{\mathbf{1}}$ & $\boldsymbol{Y}_{\mathbf{2}}$ & $5.2 \pm 0.02$ \\
12 & $40.01 \pm 0.17$ & $99.24 \pm 0.35$ & $5.25 \pm 0.04$ \\
13 & $30.89 \pm 0.22$ & $96.62 \pm 0.30$ & $5.55 \pm 0.07$ \\
14 & $18.73 \pm 0.27$ & $76.78 \pm 0.12$ & $6.15 \pm 0.01$ \\
15 & $39.47 \pm 0.38$ & $99.19 \pm 0.19$ & $6.5 \pm 0.04$ \\
16 & $29.81 \pm 0.44$ & $96.61 \pm 0.23$ & $6.95 \pm 0.09$ \\
17 & $16.94 \pm 0.19$ & $73.66 \pm 0.39$ & $7.7 \pm 0.02$ \\
18 & $37.68 \pm 0.25$ & $98.57 \pm 0.32$ & $8.1 \pm 0.01$ \\
19 & $25.17 \pm 0.31$ & $90.31 \pm 0.39$ & $8.6 \pm 0.06$ \\
20 & $14.80 \pm 0.26$ & $70.35 \pm 0.42$ & $8.25 \pm 0.04$ \\
\hline
\end{tabular}

Mean \pm S.D.; $n=3$. 


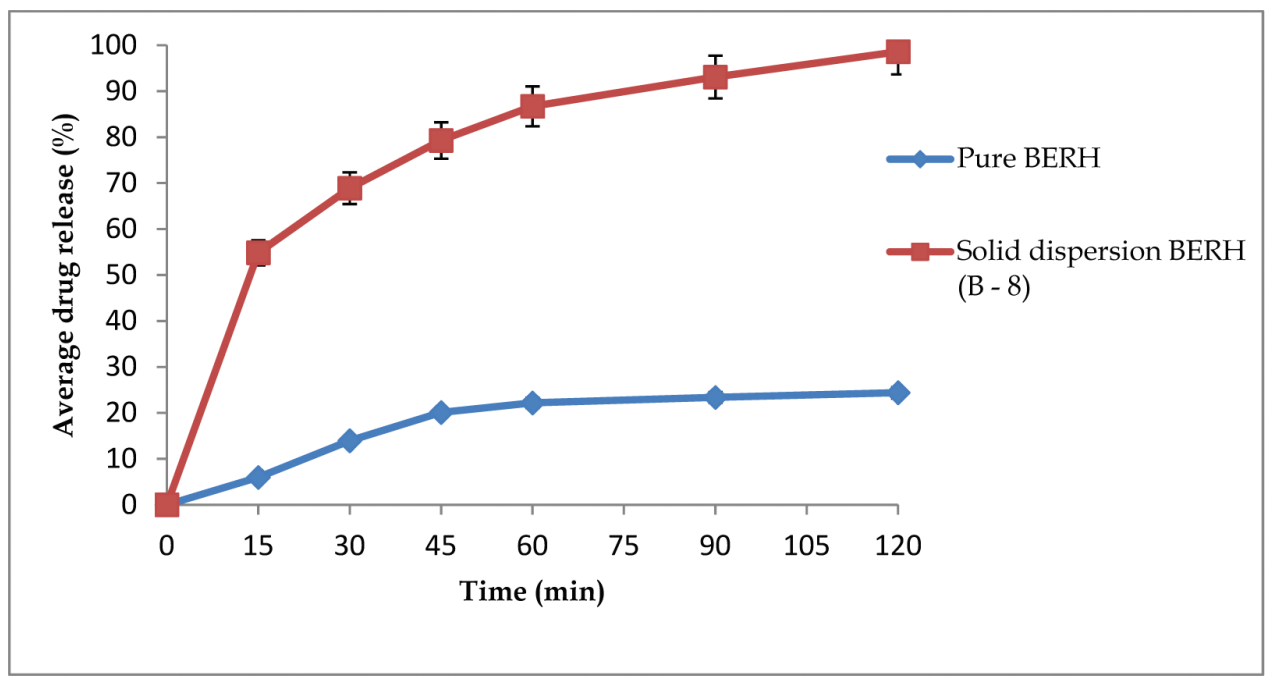

Figure 3. In vitro dissolution study of pure drug and solid dispersion batch (B 8), Mean \pm S.D.; $n=3$.

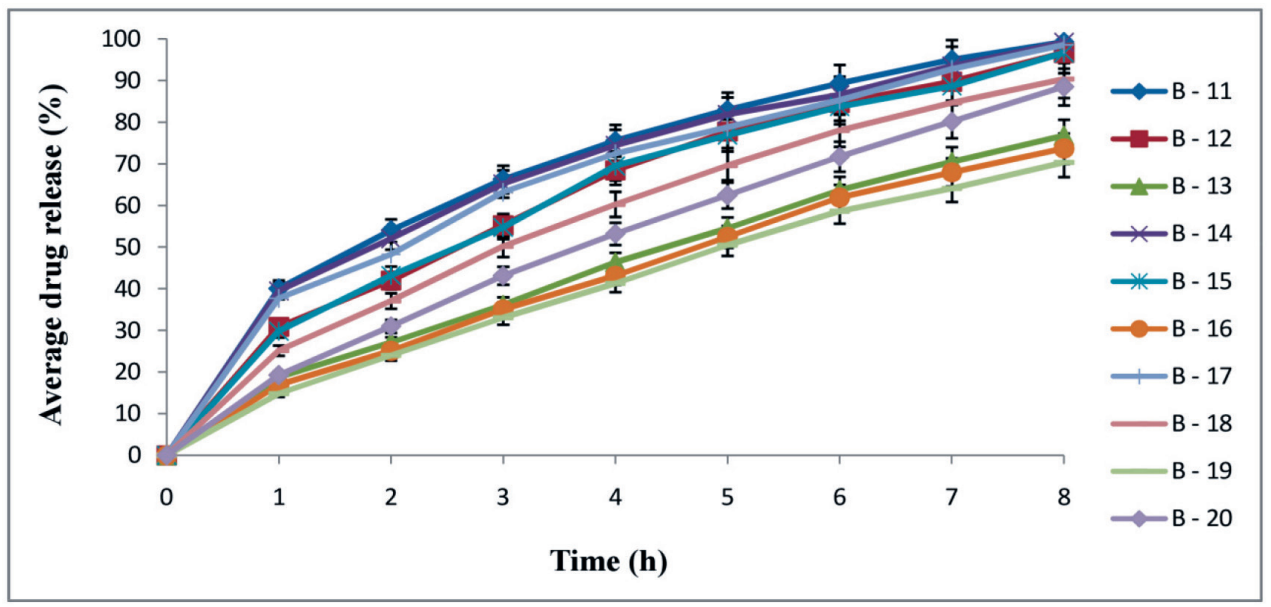

Figure 4. In-vitro dissolution study of sustain release floating pellets (batch B 11-B 20), Mean \pm S.D.; $n=3$.

high hydrophobicity of gelucire 43/01 which leads to increased lipid matrix density and diffusion path length for the drug particles to diffuse. On the surface of the lipid matrix due to the dissolution of the drug particles, formation of channels occurs from which the drug is slowly released (Jain and Gupta, 2009; Sankar and Mishra, 2003). However, no significant effect on drug release was observed by varying the amount of $\mathrm{NaHCO}_{3}: \mathrm{HPMC} \mathrm{K4M}$.

The optimized sustain release floating pellets formulation of BERH (batch B 20) was analyzed according to various mathematical models to understand the drug release kinetics. The best fit with higher correlation was found with Higuchi model or zero order shown in Table 5. The initial slight fast release was due to both dissolution and diffusion from the surface of pellets. The Korsmeyer-Peppas value of release exponent $(n)$ was 0.73 indicating that the release was governed by non-Fickian diffusion, i.e., coupled diffusion and polymer matrix relaxation (Abdelkader et al., 2008).

\section{Statistical optimization}

The responses, i.e., total floating time, drug release in 1 hour, and 8 hours for 09 batches (B-11 to B-19) were fitted into various models using design expert software. A quadratic model is suggested for all the responses, accordingly ANOVA results for response surface model was generated indicated in Table 6 . The obtained $p$ values $(<0.05)$ for all the responses indicated that the model terms are significant. The statistical parameters analyses for all the responses are shown in Table 7. For all the responses, the predicted $R^{2}$ value is in reasonable agreement with adjusted $R^{2}$ value. Adequate precision measures signal-to-noise ratio $(>4$ desirable). In all responses, the adequate precision was greater than 4 indicating an adequate signal and the model can be used to navigate the design space.

The obtained response surface plot for the total floating time and drug release in 1 and 8 hours were indicated in Figure 5. Response plot of drug release in 1 and 8 hours indicated significant effect of amount of gelucire 43/01 on drug release. The drug release decrease with increasing level of release retardant gelucire $43 / 01$. The sustain release floating pellets prepared with $20 \% \mathrm{w} / \mathrm{w}$, $25 \% \mathrm{w} / \mathrm{w}$, and $30 \% \mathrm{w} / \mathrm{w}$ of gelucire $43 / 01$ showed up to $40.01 \%$, $30.89 \%$, and $18.73 \%$ drug release, respectively, in 1 hour followed by sustained drug release in 8 hours. The drug release obtained in 
8 hours with $20 \% \mathrm{w} / \mathrm{w}, 25 \% \mathrm{w} / \mathrm{w}$, and $30 \% \mathrm{w} / \mathrm{w}$ of gelucire $43 / 01$ was up to $99.24 \%, 96.62 \%$, and $76.78 \%$, respectively. The results of dissolution studies indicated the effect of gelucire 43/01 that as the amount increases it minimizes the initial burst release with sustained drug release in 8 hours. This behavior could be attributed due to the high hydrophobicity of gelucire $43 / 01$ which provides sustain drug release. On the other side, no significant effect of amount of $\mathrm{NaHCO}_{3}: \mathrm{HPMC} \mathrm{K} 4 \mathrm{M}$ on drug release was observed. However, $\mathrm{NaHCO}_{3}$ : HPMC K4M and gelucire 43/01 significantly affects total floating time as shown by response plot of total floating time. As the amount of $\mathrm{NaHCO}_{3}: \mathrm{HPMC} \mathrm{K} 4 \mathrm{M}$ and gelucire 43/01 increases total floating time also increases. The total floating time observed with varying amount of $\mathrm{NaHCO}_{3}: \mathrm{HPMC}$ K4M was in the range of 5.2 to 5.55 hours $(10 \% \mathrm{w} / \mathrm{w}), 6.15$ to 6.95 hours $(15 \%$ $\mathrm{w} / \mathrm{w})$ and 7.7 to 8.6 hours $(20 \% \mathrm{w} / \mathrm{w})$. This could be explained as higher amount of $\mathrm{NaHCO}_{3}: \mathrm{HPMC} \mathrm{K} 4 \mathrm{M}$ was able to generate sufficient $\mathrm{CO}_{2}$ and ensured entrapment of generated $\mathrm{CO}_{2}$ inside the hydrating gel network. The floating study reveals the combined effect of independent variables, i.e., hydrophobicity provided by gelucire 43/01 with gas generating mechanism due to $\mathrm{NaHCO}_{3}$ : HPMC K4M which collectively provided buoyancy to the pellets for up to 8 hours.

The results can be correlated with the generated regression equations (A: gelucire 43/01; B: $\mathrm{NaHCO}_{3}$ : $\mathrm{HPMC}$ $\mathrm{K} 4 \mathrm{M})$. The regression equation $\left(Y_{1}\right.$ and $\left.Y_{2}\right)$ coefficients indicated that (A: gelucire 43/01) had more pronounced negative effect on drug release in 1 and 8 hours. The regression equation $\left(Y_{3}\right)$ coefficients indicated positive effect of (B: $\mathrm{NaHCO}_{3}$ : HPMC K4M) and (A: gelucire 43/01) on total floating time.

\section{Regression equations of the employed quadratic model:}

$$
\begin{aligned}
& Y_{1} \text {-Avg. drug release }(\mathbf{1} \text { hour })= 29.64-11.12 \mathrm{~A}-2.00 \mathrm{~B}- \\
& 0.95 \mathrm{~A}^{2}-1.13 \mathrm{~B}^{2}-0.40 \mathrm{AB} \\
& \mathbf{Y}_{2} \text {-Avg. drug release }(\mathbf{8} \text { hours })= 96.25-12.70 \mathrm{~A}-2.24 \mathrm{~B}- \\
& 8.79 \mathrm{~A}^{2}-1.75 \mathrm{~B}^{2}-1.44 \mathrm{AB} \\
& \mathbf{Y}_{3} \text {-Total floating time (hour) }= 6.49+0.34 \mathrm{~A}+1.40 \mathrm{~B}+0.0680 \\
& \mathrm{~A}^{2}+0.19 \mathrm{~B}^{2}+0.14 \mathrm{AB}
\end{aligned}
$$

\begin{tabular}{|c|c|c|c|c|}
\hline \multirow{2}{*}{ Batch No. } & Zero order & First order & Higuchi release & \multirow{2}{*}{$\begin{array}{c}\text { Korsmeyer-Peppas } \\
(n)\end{array}$} \\
\hline & \multicolumn{3}{|c|}{ Correlation coefficients $\left(r^{2}\right)$} & \\
\hline В 20 & 0.981 & 0.974 & 0.996 & 0.73 \\
\hline
\end{tabular}

To identify optimum formulation, desirability approach under numerical optimization function was used. The optimum formulation was obtained by applying constraints to independent

Table 5. In vitro drug release kinetics of optimized formulation. and dependent variables. Independent variables were kept in the range whereas drug release in 1 and 8 hours set to minimum and maximum, respectively, while total floating time set to maximum. The solution provided by the design expert software with highest desirability was selected indicated in Table 8. An optimized formulation (batch B 20) indicated in Table 3 was prepared and evaluated for the responses. The obtained results of drug release in 1,8 , and total floating time of batch B 20 shown in Table 4. The obtained experimental results of batch B 20 were in near proximity to the theoretical values of drug release in 1, 8 hours, and total floating time as suggested by numerical optimization function shown in Table 8 .

\section{Stability studies}

The analysis of the drug content, drug release at 8 hours and total floating time at $40^{\circ} \mathrm{C} / 75 \%$ relative humidity for 3 months, shown in Table 9. No significant changes in drug content and drug release were observed during the storage. The total floating time of pellets were also found to be near to 8 hours after 3 months. The stability studies results indicated that the developed sustain release floating pellet system of BERH were stable.

\section{In vivo Pharmacokinetics in Wistar rats}

The plasma concentration-time profiles of BERH floating pellets (B-20) and BERH marketed tablet were determined and compared shown in Figure 6. The calculated mean pharmacokinetic parameters are shown in Table 10. The drug from floating pellets was released slowly compared to the marketed tablets. The change in $C_{\max }$ and increase in $T_{\max }$ values indicated sustained drug release of prepared BERH floating pellets. The obtained value of MRT and lower elimination rate constant values indicated long resident time of BERH floating pellets. By considering $\mathrm{AUC}_{0-\infty}$ of $\mathrm{BERH}$ Pellets and BERH marketed tablet, a 2.32-fold increase in relative bioavailability was observed. One of the probable reason behind

Table 7. Summary of statistical parameters for the responses.

\begin{tabular}{lccc}
\hline \multirow{2}{*}{ Parameter } & \multicolumn{2}{c}{ Average drug release } & Total floating time \\
& $\mathbf{1}$ hour & $\mathbf{8}$ hours & 6.62 \\
\hline Mean & 28.68 & 91.39 & 0.043 \\
SD & 0.72 & 1.12 & 0.65 \\
CV & 2.52 & 1.23 & 0.999 \\
$R^{2}$ & 0.995 & 0.993 & 0.998 \\
Adjusted $R^{2}$ & 0.991 & 0.988 & 0.989 \\
Predicted $R^{2}$ & 0.958 & 0.947 & 118.73 \\
Adequate precision & 53.32 & 40.42 & \\
\hline
\end{tabular}

SD: Standard deviation; $\mathrm{CV}$ : Coefficient of variation.

Table 6. Summary of ANOVA results for response surface model.

\begin{tabular}{lcccccc}
\hline Parameter & Sum of squares & $\begin{array}{c}\text { Degrees of } \\
\text { freedom }\end{array}$ & $\begin{array}{c}\text { Mean } \\
\text { square }\end{array}$ & $\boldsymbol{F}$ value & $\boldsymbol{p}$ value Prob $>$ F & Remark \\
\hline Quadratic Model & 775.48 & Average drug release (1 hour) & significant \\
Quadratic Model & 1303.40 & Average drug release (8 hours) & 295.99 & $<0.0001$ & significant \\
Quadratic Model & 5 & 260.88 & 206.91 & $<0.0001$ & significant \\
\hline
\end{tabular}



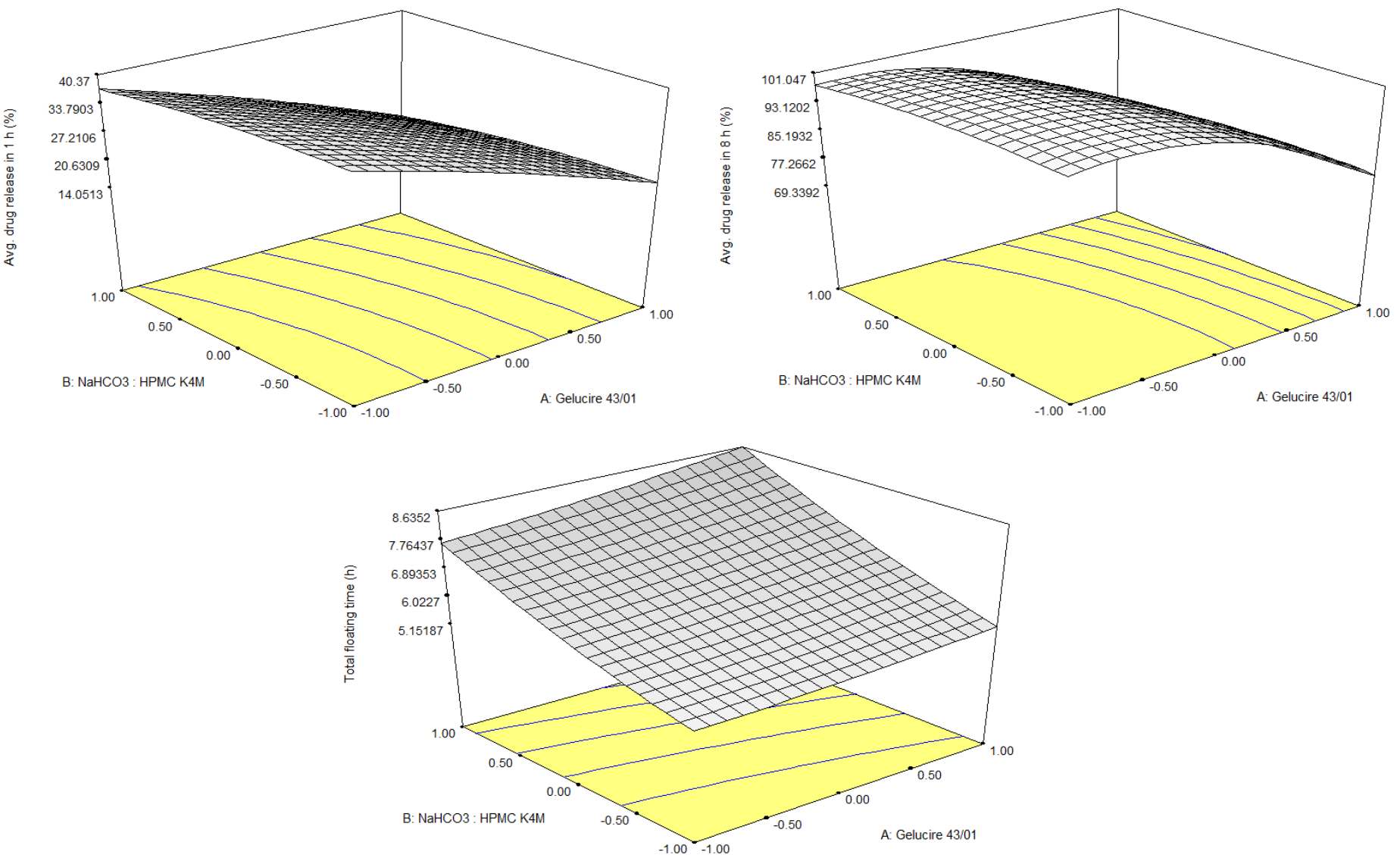

Figure 5. Response surface plots of drug release in 1, 8 hours and total floating time.

Table 8. Summary of numerical optimization.

\begin{tabular}{lcccc}
\hline Parameters & Goal & Solution & Desirability & Remark \\
\hline \multicolumn{5}{c}{ Independent variables } \\
Gelucire 43/01 & In range & $+0.5(27.5 \%)$ & & \\
$\mathrm{NaHCO}_{3}:$ HPMC K4M & In range & $+1(20 \%)$ & & \\
\multicolumn{5}{c}{ Dependent Variables } \\
Percent drug release in 1 hour & Minimum & $21.77 \%$ & & \\
Percent drug release in 8 hours & Maximum & $85.88 \%$ & \\
Total floating time & Maximum & $8.28 \mathrm{~h}$ & \\
\hline
\end{tabular}

Table 9. Accelerated stability study results for formulation (B 20).

\begin{tabular}{cccc}
\hline Month & $\begin{array}{c}\text { Drug content } \\
(\mathbf{\%})\end{array}$ & $\begin{array}{c}\text { Drug release at } 8 \text { hours } \\
(\mathbf{\%})\end{array}$ & $\begin{array}{c}\text { Total floating time } \\
\text { (hour) }\end{array}$ \\
\hline 0 & $97.85 \pm 1.21$ & $88.46 \pm 0.78$ & $8.25 \pm 0.04$ \\
1 & $97.44 \pm 1.05$ & $88.94 \pm 0.49$ & $8.20 \pm 0.04$ \\
2 & $96.25 \pm 0.88$ & $87.37 \pm 0.66$ & $7.95 \pm 0.07$ \\
3 & $96.04 \pm 0.92$ & $86.46 \pm 1.14$ & $7.9 \pm 0.01$ \\
\hline
\end{tabular}

Mean \pm S.D.; $n=3$.

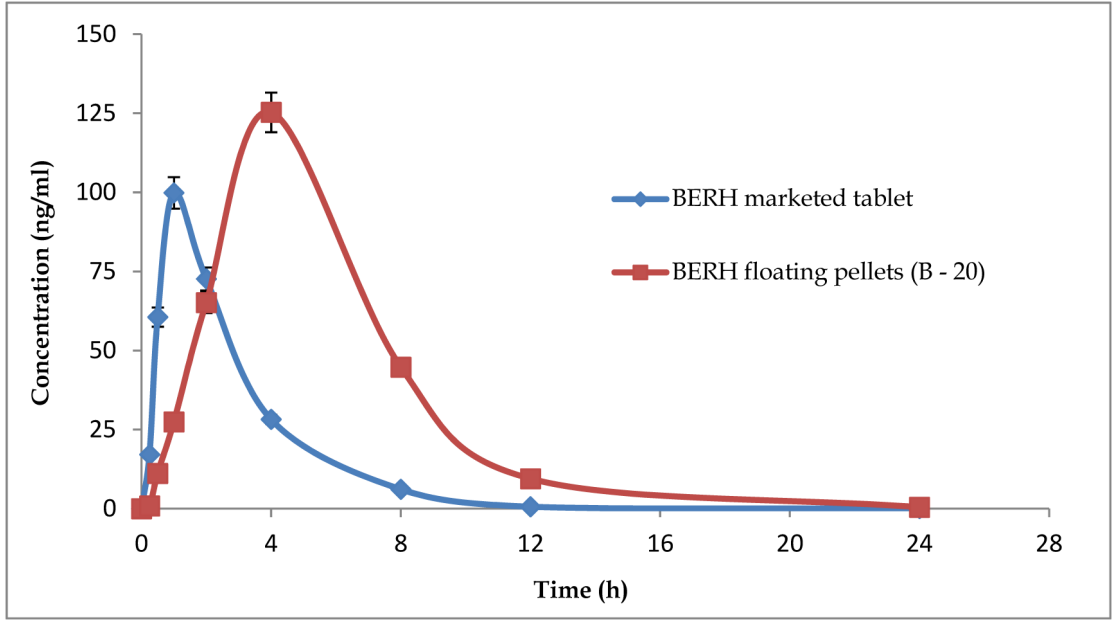

Figure 6. Time versus mean plasma concentration profiles of BERH floating pellets and BERH marketed tablet, mean $\pm \mathrm{SD} ; n=6$. 
Table 10. Pharmacokinetics of BERH floating pellets and marketed tablet.

\begin{tabular}{lcc}
\hline Parameters & BERH floating Pellets (B-20) & BERH marketed tablet \\
\hline$C_{\max }(\mathrm{ng} / \mathrm{ml})$ & $125.31 \pm 1.13^{*}$ & $99.86 \pm 0.78$ \\
$T_{\max }(\mathrm{h})$ & $4.00 \pm 0.16^{*}$ & $1.00 \pm 0.22$ \\
$\mathrm{AUC}_{0-\infty}(\mathrm{ng}-\mathrm{h} / \mathrm{ml})$ & $757.58 \pm 6.13^{*}$ & $326.10 \pm 4.26$ \\
$\mathrm{MRT}($ hour$)$ & $5.95 \pm 0.04^{*}$ & $2.80 \pm 0.01$ \\
$\mathrm{Ke}\left(\right.$ hour $\left.^{-1}\right)$ & $0.23 \pm 0.13^{*}$ & $0.47 \pm 0.17$
\end{tabular}

Relative bioavailability: AUC of BERH Pellets B- 20 /AUC of BERH tablet $=2.32$

${ }^{*} p<0.05$ as compared to marketed tablet, Mean \pm S.D.; $n=6$.

this could be as BERH is an P-gp substrate which is responsible for its active efflux from the intestine. The P-gp expression increases progressively from the proximal to distal small intestine. The gastroretentive floating pellets possibly prevented the efflux of BERH through intestine by keeping the drug in upper GIT, and allowed its continuous absorption through proximal part of the GIT which probably leads to significant improvement in relative bioavailability compared to the marketed tablet. The statistical analysis revealed significant difference in the $C_{\max }, T_{\max }, \mathrm{AUC}$, and MRT values.

\section{CONCLUSION}

In the current study, solid dispersion of BERH prepared using hydrophilic carrier gelucire 50/13 in the ratio of 1:2 (batch B-8) compared to pure BERH showed significant improvement in aqueous solubility $(2.841 \pm 0.15 \mathrm{mg} / \mathrm{ml} \mathrm{vs.} 0.718 \pm 0.02 \mathrm{mg} /$ $\mathrm{ml})$ and dissolution behavior $(98.59 \%$ vs. $24.39 \%$ drug release in 2 hours). The solid dispersion of BERH (batch B-8) further formulated into sustain release floating pellets using hydrophobic lipid carrier gelucire 43/01 as release retardant, $\mathrm{NaHCO}_{3}$, and HPMC K4M as gas former and matrix polymer, respectively. An optimized formulation (batch B-20) comprising of gelucire 43/01 $\left(27.5 \% \mathrm{w} / \mathrm{w}\right.$ of solid dispersion) $\mathrm{NaHCO}_{3}$ :HPMC K4M (1:0.5; $20 \% \mathrm{w} / \mathrm{w}$ of solid dispersion) was identified using numerical optimization function by Design expert software. It showed total floating time for more than 8 hours and $88.46 \%$ drug release in 8 hours. The pharmacokinetic study conducted in male Wistar rats showed increased $C_{\max }$, prolonged $T_{\max }$, and MRT collectively demonstrated sustained drug release. The relative bioavailability of optimized formulation was improved by 2.32 -fold in comparison to marketed BERH tablet. The floating pellets of BERH with improved bioavailability were obtained and could be an applicable choice for enhancing the systemic delivery so as to optimize its clinical use.

\section{AUTHORS' CONTRIBUTION STATEMENT}

Both the authors have made an active contribution to the conception and design and/or analysis and interpretation of the data and/or the drafting of the paper and have critically reviewed its content and have approved the final version submitted for publication. Both the authors are accountable for all the aspects of the work and ensure that questions related to the accuracy or integrity of any part of the work are appropriately investigated and resolved.

\section{ACKNOWLEDGMENT}

The authors would like to thank the Dr. S. S. Chitlange for providing kind support to carry out the research work. The authors acknowledges to Gattefosse India Pvt. Ltd., Mumbai, India for providing gift sample of Gelucire 43/01, Gelucire 44/14, Gelucire 50/13 and Compritol 888.

\section{CONFLICTS OF INTEREST}

The authors declared that they have no conflict of interest.

\section{FINANCIAL SUPPORT}

This research did not receive any specific grant from funding agencies in the public, commercial, or not-for-profit sectors.

\section{ETHICAL APPROVAL}

All experimental procedures were performed in accordance with the ethical guidelines for the study and were approved by the Institutional Animal Ethical Committee (DYPIPSR/IAEC/18-19/P-10), Dr. D. Y. Patil Institute of Pharmaceutical Sciences and Research, Pune, Maharashtra, India.

\section{REFERENCES}

Abdelkader H, Youssef Abdalla O, Salem H. Formulation of controlled-release baclofen matrix tablets II: Influence of some hydrophobic excipients on the release rate and in vitro evaluation. AAPS PharmSciTech, 2008; 9:675-83.

Alolga R, Fan Y, Chen Z, Liu L, Zhao Y, Li J, Chen Y, Lai M, Li P, Qi L. Significant pharmacokinetic differences of berberine are attributable to variations in gut microbiota between Africans and Chinese. Sci Rep, 2016; 6:27671.

Anaoui A, Vergnaud JM. Modelling the plasma drug level with oral controlled release dosage forms with lipidic Gelucire. Int J Pharm, 1998; 169:155-62.

Barker SA, Yap SP, Yuen KH, McCoy CP, Murphy JR, Craig DQM. An investigation into the structure and bioavailability of $\alpha$-tocopherol dispersions in Gelucire 44/14. J Control Release, 2003; 91:477-88.

Bulgarelli E, Forni F, Bernabei MT. Effect of matrix composition and process conditions on casein-gelatin beads floating properties. Int J Pharm, 2000; 198:157-65.

Chang Y. Effectiveness of berberine in bacillary dysentery. Zhonghua Nei Ke Za Zhi, 1959; 7:741-3.

Costa P, Lobo MS. Modeling and comparison of dissolution profiles. Eur J Pharm Sci, 2001; 13:123-33.

Daravath B, Tadikonda RR, Vemula SK. Formulation and pharmacokinetics of gelucire solid dispersions of flurbiprofen. Drug Dev Ind Pharm, 2015; 41:1254-62.

Davis SS. Formulation strategies for absorption windows. Drug Discov Today, 2005; 10:249-57.

Douroumis D, Bouropoulos N, Fahr A. Physicochemical characterization of solid dispersions of three antiepileptic drugs prepared by solvent evaporation method. J. Pharm. Pharmacol, 2007; 59:645-53.

El-Badry M, Fathy M. Enhancement of the dissolution and permeation rates of meloxicam by formation of its freeze-dried solid dispersions in polyvinylpyrrolidone K-30. Drug Dev Ind Pharm, 2006; 32:141-50.

El-Badry M, Fathy M. Properties of solid dispersion of piroxicam in Pluronic F-98. J Drug Deliv Sci Technol, 2015; 14:199-205.

Elsamaligy S, Bodmeier R, Development of extended release multiple unit effervescent floating drug delivery systems for drugs with different solubilities. J Drug Deliv Sci Technol, 2015; 30:467-77.

Fan D, Wu X, Dong W, Sun W, Li J, Tang X. Enhancement by sodium caprate and sodium deoxycholate of the gastrointestinal absorption of berberine chloride in rats. Drug Dev Ind Pharm, 2013; 39:1447-56.

Gao S, Basu S, Yang G, Deb A, Hu M. Oral bioavailability challenges of natural products used in cancer chemoprevention. Prog Chem, $2013 ; 25: 1553-74$ 
Guo S, Wang G, Wu T, Bai F, Xu J, Zhang X. Solid dispersion of berberine hydrochloride and Eudragit ${ }^{\circledR}$ S100: Formulation, physicochemical characterization and cytotoxicity evaluation. J Drug Deliv Sci Technol, $2017 ; 40: 21-7$.

Higuchi T. Mechanism of sustained action medication: theoretical analysis of rate release of solid drugs dispersed in solid matrices. J Pharm Sci, 1963; 52:1145-9.

Hoffman A, Stepensky D, Lavy E, Eyal S, Klausner E, Friedman M. Pharmacokinetic and pharmacodynamic aspects of gastroretentive dosage forms. Int J Pharma, 2004; 277:141-53.

Iannuccelli V, Coppi G, Bernabei MT, Cameroni R. Air compartment multiple-unit system for prolonged gastric residence. Part I. Formulation study. Int J Pharm, 1998; 174:47-54.

Jain SK, Gupta A. Development of gelucire 43/01 beads of metformin hydrochloride for floating delivery. AAPS PharmSciTech, 2009; 10:1128-36.

Jain SK, Jangdey MS. Lectin conjugated gastroretentive multiparticulate delivery system of clarithromycin for the effective treatment of Helicobacter pylori. Mol Pharm, 2009; 6:295-304.

Jantova S, Cipak L, Cernakova M, Kostalova D. Effect of berberine on proliferation, cell cycle and apoptosis in HeLa and L1210 cells. J Pharm Pharmacol, 2003; 55:1143-9.

Kagan L, Hoffman A. Systems for region selective drug delivery in the gastrointestinal tract: biopharmaceutical considerations. Expert Opin Drug Deliv, 2008; 5:681-92.

Kawakami K, Miyoshi K, Ida Y. Solubilization behavior of poorly soluble drugs with combined use of Gelucire 44/14 and cosolvent. J Pharm Sci, 2004; 93:1471-9.

Ke Z, Zhu ZP, Xu ZY, Fang C, Hu SQ. Formulation design and in vitro evaluation of berberine-loaded self-nanoemulsifying drug delivery system. Trop J Pharm Res, 2015; 14:747-52.

Kettmann V, Kostalova D, Jantova S, Cernakova M, Drimal J. In vitro cytotoxicity of berberine against $\mathrm{HeLa}$ and $\mathrm{L} 1210$ cancer cell lines. Pharmazie, 2004; 59:548-51.

Khayam MU, Khurram M, Amin MU, Haseeb A, Kakar M. Berberine nanoparticles with enhanced in vitro bioavailability: characterization and antimicrobial activity. Drug Des Devel Ther, 2018; 12:303-12.

Kim MS, Kim JS, Hwang SJ. The effect of sodium alginate on physical and dissolution properties of Surelease ${ }^{\circledR}$-matrix pellets prepared by a novel pelletizer. Chem Pharm Bull, 2007; 55:1631-4.

Kong W, Wei J, Abidi P, Lin M, Inaba S, Li C, Wang Y, Wang Z, Si S, Pan H, Wang S, Wu J, Wang Y, Li Z, Liu J, Jiang JD. Berberine is a novel cholesterol-lowering drug working through a unique mechanism distinct from statins. Nat Med, 2004; 10:1344-51.

Korsmeyer RW, Gurny R, Doelker E, Buri P, Peppas NA. Mechanisms of solute release from porous hydrophilic polymers. Int J Pharm, 1983; 15:25-35.

Kosalec I, Gregurek B, Kremer D, Zovko, M, Sankovic K, Karlovic K. Croatian barberry (Berberis croatica Horvat): a new source of berberine-analysis and antimicrobial activity. World J Microb Biot, 2009; 25:145-50.

Kotreka UK, Adeyeye MC. Gastroretentive floating drugdelivery systems: a critical review. Crit Rev Ther Drug Carrier Syst, 2011; 28:47-99.

Lee YS, Kim WS, Kim KH, Yoon MJ, Cho HJ, Shen Y, Ye JM, Lee CH, Oh WK, Kim CT, Behrens CH, Gosby A, Kraegen EW, James DE, Kim JB. Berberine, a natural plant product, activates AMP-activated protein kinase with beneficial metabolic effects in diabetic and insulin-resistant states. Diabetes, 2006; 55:2256-64.

Lopes CM, Lobo JMS, Pinto JF, Costa P. Compressed minitablets as a biphasic delivery system. Int J Pharm, 2006; 323:93-100.

Maeng HJ, Yoo HJ, Kim IW, Song IS, Chung SJ, and Shim CK. P-glycoprotein-mediated transport of berberine across Caco-2 cell monolayers. J Pharm Sci, 2002; 92:2614-21.
Maurya SK, Bali V, Pathak K. Bilayered transmucosal drug delivery system of pravastatin sodium: Statistical optimization, in vitro, ex vivo, in vivo and stability assessment. Drug Deliv, 2012; 19:45-57.

Mehuys E, Vervaet C, Remon JP. Hot-melt extruded ethylcellulose cylinders containing a HPMC-Gelucire ${ }^{\circledR}$ core for sustained drug delivery. J Control Release, 2004; 94:273-80.

Pagariya TP, Patil SB, Development and optimization of multiparticulate drug delivery system of alfuzosin hydrochloride. Colloids Surfaces B Biointerfaces, 2013;102:171-7.

Pan GY, Wang GJ, Liu XD, Fawcett JP, Xie YY. The involvement of P-glycoprotein in berberine absorption. Pharmacol Toxicol, 2002; 91:193-7.

Parmar SS, Mishra RV, Shirolkar SV. Spherical agglomeration a novel approach for solubility and dissolution enhancement of simvastatin. Asian J Pharm Clin Res, 2016; 9:65-72.

Pawar YB, Purohit H, Valicherla GR, Munjal B, Lale SV, Patel SB, Bansal AK. Novel lipid based oral formulation of curcumin: development and optimization by design of experiments approach, Int. J. Pharm, 2012; 436:617-23

Pestieau A, Krier F, Lebrun P, Brouwers A, Streel B, Evrard B. Optimization of a PGSS (particles from gas saturated solutions) process for a fenofibrate lipid-based solid dispersion formulation. Int J Pharm, 2015; 485:295-305.

Rajinikanth PS, Karunagaran LN, Balasubramaniam J, Mishra B. Formulation and evaluation of clarithromycin microspheres for eradication of helicobacter pylori. Chem Pharm Bull, 2008; 56: 1658-1664.

Reddy LH, Murthy RS. Floating dosage systems in drug delivery. Crit Rev Ther Drug Carrier Syst, 2002; 19:36.

Ritger PL, Peppas NA. A simple equation for description of solute release. II. Fickian and anomalous release from swellable devices. J Controlled Release, 1987; 5:37-42.

Sailor G, Seth AK, Parmar G, Chauhan S, Javia A. Formulation and in vitro evaluation of berberine containing liposome optimized by 32 full factorial designs. J Appl Pharm Sci, 2015; 5(7):23-8.

Sanchez CJ. Increase in action potential duration and inhibition of the delayed rectifier outward current IK by berberine in cat ventricular myocytes. Br J Pharmacol, 1996; 117:1427-34.

Sankar C, Mishra B. Development and in vitro evaluations of gelatin A microspheres of ketorolac tromethamine for intranasal administration. Acta Pharm, 2003; 53:101-10.

Seo A, Holm P, Kristensen HG, Schæfer T. The preparation of agglomerates containing solid dispersions of diazepam by melt agglomeration in a high shear mixer. Int J Pharm, 2003; 259:161-71.

Shaker MA. Dissolution and bioavailability enhancement of Atorvastatin: Gelucire semi-solid binary system. J Drug Deliv Sci Technol, 2018; 43:178-84.

Shen N, Li X, Zhou T, Bilala MU, Du N, Hu Y, Qin W, Xie Y, Wang H, Wu J, Ju J, Fang Z, Wang L, Zhang Y. Shensong Yangxin capsule prevents diabetic myocardial fibrosis by inhibiting TGF- $\beta 1 /$ Smad signaling. J Ethnopharmacol, 2014; 157:161-70.

Sheu MT, Hsia AHO. Polyglycolized saturated glycerides as carrier and enhancer for drug penetration. Chin Pharm J, 2001; $53: 107-11$

Shimpi S, Chauhan B, Mahadik KR, Paradkar A. Preparation and evaluation of diltiazem hydrochloride-gelucire 43/01 floating granules prepared by melt granulation. AAPS PharmSciTech, 2004; 5:51-6.

Sruti J, Patra CN, Swain S, Panigrahi KC, Patro AP, Beg S, Dinda SC, Rao MEB. Improvement in the dissolution rate and tableting properties of cefuroxime axetil by melt-granulated dispersion and surface adsorption. Acta Pharm Sin B, 2013; 3:113-22

Streubel A, Siepmann J, Bodmeier R. Gastroretentive drug delivery systems. Expert Opin Drug Deliv, 2006; 3:217-33.

Streubel A, Siepmann J, Bodmeier R. Multiple unit gastroretentive drug delivery systems: a new preparation method for low density microparticles. J Microencapsul, 2003; 20:329-47. 
Strusi OL, Sonvico F, Bettini R, Santi P, Colombo G, Barata P, Oliveira A, Santos D, Colombo P. Module assemblage technology for floating systems: In vitro flotation and in vivo gastro-retention. J Control Release, 2008; 129:88-92.

Svensson A, Neves C, Cabane B. Hydration of an amphiphilic excipient, Gelucire $^{\circledR}$ 44/14. Int J Pharm, 2004; 281:107-18.

Tan W, Li Y, Chen M, Wang Y. Berberine hydrochloride: anticancer activity and nanoparticulate delivery system. Int J Nanomedicine, $2011 ; 6: 1773-7$.

Thybo P, Kristensen J, Hovgaard L. Characterization and physical stability of tolfenamic acid-PVP K30 solid dispersions. Pharm Dev Technol, 2007; 12:43-53.

Tsai PL, Tsai TH. Hepatobiliary excretion of berberine. Drug Metab Dispos, 2004; 32:405-12.

Venkata SM, Sreenivasa RN, Ambedkar SS, Janaki RB, Kolapalli VRM. Statistical design and evaluation of a propranolol $\mathrm{HCl}$ gastric floating tablet. Acta Pharm Sin B, 2012; 2:60-9.

Wei Chen W, Miao YQ, Fan DJ, Yang SS, Lin X, Meng LK, Tang $X$. Bioavailability study of berberine and the enhancing effects of TPGS on intestinal absorption in rats. AAPS PharmSciTech, 2011; 12:705-11.
Yang D, Kulkarni R, Behme RJ, Kotiyan PN. Effect of the melt granulation technique on the dissolution characteristics of griseofulvin. Int J Pharm, 2007; 329:72-80.

Zhang Y, Cui YL, Gao LN, Jiang HL. Effects of $\beta$-cyclodextrin on the intestinal absorption of berberine hydrochloride, a P-glycoprotein substrate. Int J Biol Macromol, 2013; 59:363-71.

Zhu JX, Tang D, Feng L, Zheng ZG, Wang RS, Wu AG, Duan TT, He B, Zhu Q. Development of self-microemulsifying drug delivery system for oral bioavailability enhancement of berberine hydrochloride. Drug Dev Ind Pharm, 2013; 39:499-506.

How to cite this article:

Mishra R, Dhole S. Lipid-based floating multiparticulate delivery system for bioavailability enhancement of berberine hydrochloride. J Appl Pharm Sci, 2019; 9(11):036-047. 